\title{
The Awareness of HIV/AIDS in Small Enterprises in a Sector of the Fast Moving Consumer Goods Trade in South Africa
}

\author{
C Anders \\ Jumbo Foods, Polokwane \\ M M Botha \\ Department of Postgraduate Studies and Research, University of Port Elizabeth
}

\begin{abstract}
This research sought to determine the level and nature of awareness of owners/managers of small enterprises in the fast moving consumer goods (FMCG) trade in the rural areas of the Limpopo Province, regarding the threat of HIV/AIDS to their businesses. The results indicated that information campaigns that target these businesses need to be intensified and that owners and managers of businesses should be trained to educate their employees and in developing and implementing business strategies to cope with the threat of HIV/AIDS. The government also needs to play a greater role in combating HIV/AIDS. The two major recommendations are that an appropriate information campaign specifically focused on the needs of this business sector be developed, as well as a model that could be used to manage HIV/AIDS.
\end{abstract}

JEL 112, L81

\section{1}

\section{Background}

The life-threatening HIV/AIDS virus is affecting the life-styles of the infected as well as the non-infected dramatically. No proven cure has officially been identified and the best current strategy seems to be to sustain and prolong the lifespan of the infected, hoping that a cure will be found in time.

The extent of HIV/AIDS globally and in South Africa is such that all dimensions of society, including business and trade, need to make some adjustment to it. According to estimates from the ongoing United Nations Program on HIV/AIDS (UNAIDS) 34.7 million adults and 1.4 million children were living with HIV worldwide at the end of 2000. About 95 per cent of the global HIV infected population is living in the developing world or third world countries.

South Africa has been cited as the country with the fastest growth rate of this epidemic, with the highest prevalence between the ages of 20 and 44 (2001). The provinces with the highest rates of infection were indicated then as KwaZulu-Natal (32.5 per cent), Mpumalanga (30.0 per cent) and the Free State (22.8 per cent). It was estimated that 4 million South Africans were infected in 2000 and that this figure would rise to 6 million in 2005 and 7 million by 2010 (Mbeki, 2001: 13). These figures have been updated regularly since 2001, but the picture remains a grim one with serious implications for all dimensions of society.

HIV/AIDS is expected to have a huge negative effect on population growth in South Africa: where the expected growth would have been from 43.7 million in 1999 to 51.3 million in 2010, now it would reach 47 million only in the best case scenario (excluding migration), with the worst case scenario being a negative growth rate by 2080 (Whiteside \& Sunter, 2000: 69-71). 
In was recently reported in the press that a Kenyan study as well as surveys in Mali, Zambia and South Africa had over-estimated HIV/ AIDS figures (Van Rooyen \& The Telegraph, 2004: 1). This type of reporting places doubts on the seriousness of the impact of HIV/AIDS and makes statistics like those quoted above questionable.

Commenting on the latter-mentioned studies, the same press article, however, mentioned that the lower figures reported by these studies could be the result of the absence of many people from random surveys and the reluctance of others to answer questions in such surveys; the Kenyan study was also labelled as unreliable. Another opinion in the press is that "Africa's HIV/Aids statistics are inexact but this does not mean that they are inflated. Nor does the inexactitude detract from the scale, or the severity, of the epidemic" (Keeton, 2004: 18).

The research reported on in this article was carried out with an attitude similar to the latter opinion.

\section{2}

\section{The expected impact of HIV/AIDS on the South African economy}

Most South African companies are not concerned with the implications AIDS might have for them. They also do not want to see themselves as vulnerable (Keeton, 2003a: 3). Emdon (2003: 6) reports that "as little as 1 per cent of industry and commerce are acting in an informed, collaborative way with regard to the HIV/Aids pandemic". In spite of this negative picture, it seems as though there are some glimmers of hope, as the South African Business Coalition Against Aids, launched in 2001, reported that there is an increase in "inquiries from firms wanting to establish HIV/AIDS workplace programmes" and that the willingness of CEOs to get personally involved in HIV/AIDS issues is further proof of the increased sense of urgency regarding this matter (Keeton, 2003b: 6). Bennett (2003: 11) also reports that the "Chemical Industries Education and Training Authority has commissioned a multi-pronged programme to help 150 companies manage HIV/AIDS".
The impact of HIV/AIDS on the economy of South Africa depends on the type and number of people who are infected and die of the disease. If these people are mainly consumers, the impact will be different from that if they are mainly producers. Alan Whiteside says that if "the majority of those who are infected are unemployed, subsistence farmers or unskilled workers, then the impact on the economy will not be as great as if they are skilled and highly productive members of society. The same is true of savings. If the resources spent on care are considerable and come out of savings, then this will have a greater effect on the economy than if people do not spend money or the state provides care" (Whiteside \& Sunter 2000: 85).

Barnett and Whiteside (2002: 271-94) set out the threat to the South African economy by HIV/AIDS as follows:

- The labour pool of skilled workers will be depleted.

- South Africa's economic growth rate will drop by 0.3 to 0.4 percentage points by 2017 .

- Foreign investors will be deterred.

- Resources will be diverted from savings to care.

- The decrease in public, corporate and personal savings will cause an upward drive in the cost of capital.

- Interest rates will come under pressure due to smaller savings and a rise in inflation.

- International competitiveness will be reduced as AIDS increases production costs.

- As government expenditure on HIV/AIDS increases, direct government investment in areas such as infrastructure will decrease.

3

\section{The research problem, research question and research aim}

From the previous overview it is clear that the impact of HIV/AIDS on the economy in general and therefore on small businesses in particular, will manifest itself in a wide range of issues, including increased healthcare costs, 
an increase in employee absenteeism, low morale in the workplace, increased accident rate in the workplace, decreasing productivity, increased training and recruitment costs, loss of key employees, increased rate of employee turnover, increased salary bill and escalating customer loss, as well as unprecedented changes in consumer behaviour and consumer spending.

The problems and responsibilities relating to HIV/AIDS that managers of small businesses are confronted with could be categorised as follows:

- impact on the workforce;

- impact on costs (direct and indirect);

- impact on the customer base/target market;

- impact on the business environment;

- $\quad$ social responsibility of the small business.

This research was undertaken with the purpose of finding an answer to the question:

To what extent are owners/managers of small enterprises in the FMCG trade aware of the threat and impact of HIV/AIDS to/on their businesses?

The aim of the research reported on in this article was to determine the level and nature of awareness of owners/managers of small enterprises in the FMCG trade regarding the threat and impact of HIV/AIDS to/on their businesses.

\section{4}

\section{Research approach, design and methodology}

\subsection{Research approach and design}

The research approach is quantitative. A nonexperimental research design, viz. that of descriptive research, was chosen, as the nature of the problem demands this. Data was collected on the awareness of business owners and managers regarding the threat to and impact of HIV/AIDS on their businesses. Sekaran (2000: 126) states that descriptive studies "help to (1) understand the characteristics of a group in a given situation, (2) think systematically about aspects in a given situation, (3) offer ideas for further probe and research, and/or (4) help make certain simple decisions ...", thus, indicating this to be the most appropriate approach for this study.

\section{Population}

As the definition of population units depends on the subject that is being studied (Sudman \& Blair, 1998: 335), the most appropriate unit for this study has been identified as small businesses. The population boundaries were contained in the customer list of a large wholesaler situated in the Limpopo province during mid-2002. This list totals 1137 businesses at the lower end of the FMCG (fastmoving consumer goods) trade, e.g. independent mini-markets, supermarkets and butchers. These businesses are all situated in the suburban and rural areas of the Limpopo and Mpumalanga provinces. This choice of population does, however, have a limitation in that the results of the research could only be generalized to similar populations. This is not a serious limitation, as such similar populations could reasonably be expected to exist in many developing countries.

\section{Sample}

The most essential components of designing good descriptive research are subject selection and instrumentation (McMillan \& Schumacher, 1993: 270) and therefore, these two aspects needed specific attention in this research design.

Convenience (also called accidental or availability) sampling (which is a nonprobability sampling method) was used. Such a sample is chosen purely on the basis of availability (Bless \& Higson-Smith, 1995: 88, McMillan \& Schumacher, 1993: 160, Struwig \& Stead, 2001: 111). The researcher who collected the data for this research had to travel according to a specific travel plan determined by financial, geographical and vehicular constraints. The travel plan was designed to optimise participation by the whole range of elements from the population, but a truly stratified sample proved uneconomical.

Eventually 125 small businesses were visited. As the data source need not be the same as the population member (Sudman \& Blair, 1998: $335)$, the owners or managers of the small 
businesses were the data sources. Of these the owners/managers of four small businesses refused to participate and 121 participated voluntarily. Of the 121 completed questionnaires, 14 were spoilt and unusable, therefore 107 completed questionnaires were analysed. This reflects a usable response rate of 85.6 per cent. In spite of this high response rate, the results of this research cannot be unconditionally generalised, as the nature of convenience sampling precludes this. This must be noted as a limitation of the design.

\section{Instrument}

As indicated above, the choice/design of instrumentation in descriptive research is crucial to the strength of the research design. The researcher took care to ensure that the instrument was valid, as described below.

A questionnaire or interview was the most appropriate instrument to gather data for this research project, but with a sample of 125 , the latter would have been extremely timeconsuming and therefore uneconomical. A questionnaire, on the other hand, would ensure anonymity, which is an important issue in HIV/ AIDS research. Based on these arguments, a questionnaire was chosen as the most appropriate data collection instrument.

In order to formulate appropriate questions for the questionnaire, a list of specific objectives was defined regarding the information required. This was achieved by identifying information-rich business people who service the small enterprises in the sample and conducting focus group discussions with them (Bless \& Higson-Smith, 1995: 113) with a maximum of five people in a group. These participants are well informed about many aspects of the nature of these small businesses and were able to assist in formulating objectives of the questionnaire, identifying potential problem areas, acting as a sounding board and drafting a framework for the questions.

The questions were then formulated according to the guidelines for constructing a questionnaire as set out in many textbooks on research (Bless \& Higson-Smith, 1995: 115-22, McMillan \& Schumacher, 1993: 240-
2, Proctor 2000: 160-70, Struwig \& Stead, 2001: 89-96).

Additional to the above-mentioned guidelines, the questionnaire also had to accommodate the various educational levels of the respondents as well as the language barriers, as English is not the first language to most of them. The first language of respondents is one of the following: Afrikaans, English, Greek, Northern Sotho, Portuguese, Southern Sotho, Tswana or Venda. The fact that the information was collected not using the mother tongue of each respondent is a limitation of this research and should be taken into account when the results of the research are considered. Unfortunately, the cost of employing an interpreter for many of the languages involved (at least six) and drafting a time schedule for visits to business sites to accommodate both the language and travel routes would have made the research economically unviable and this option could therefore not be considered.

\section{Data collection}

The researcher personally visited each business site. The questionnaires were explained to respondents individually and left with them to complete in their own time. If a respondent still had not completed the questionnaire and/or had any queries regarding its content or language at the time that it was collected, the researcher made the necessary explanations and, if necessary, a later date for collection was agreed upon.

\section{5}

\section{Data analysis and interpretation}

The responses to the questions in the questionnaire were tabulated to identify patterns and edited "to make the best sense of what is in hand" (Proctor, 2000: 235).

The responses are summarised below with a brief interpretation in each case:

1. 97.2 per cent (104) of the respondents indicated that they are aware of the HIV/ AIDS epidemic. This implies that 2.8 per cent of the sample knows nothing of the dangers of the disease to the community 
and businesses, how it could affect trade; they are by implication ill-prepared for the pandemic or ill-advised about it. This is cause for concern on the one hand, but on the other hand it means that there is a very high level of AIDS awareness in this business community.

2. 82.3 per cent (88) of the respondents indicated that their employees are aware of HIV/AIDS. 3.7 per cent said the opposite and a significant 14 per cent (15) had no idea about their employees' awareness of the subject. The latter could be because of a laissez faire attitude to the diseases, which necessitates intervention.

3. 12.1 per cent (13) of the respondents recorded that some of their employees are infected with HIV/AIDS, 43 per cent (46) indicated that none of their employees was infected, while 44.9 per cent (48) had no idea whether any of their employees were infected. Given the official figures on the infection rate in the Limpopo Province (see section on literature review) and the legal protection regarding disclosure of the disease, it is hoped that some of the respondents had the confidence of their employees.

4. 43.9 per cent (47) of the respondents indicated that they believe their businesses are at risk of HIV/AIDS. 29.9 per cent (32) did not believe this and 26.2 per cent (28) had no idea whether their businesses are at risk. When comparing this set of responses with the first set above, the deduction could be made that, although the awareness of the HIV/AIDS epidemic is quantitatively high (97.2 per cent), the quality of that awareness could be regarded as low (56.1 per cent). This situation needs to be addressed urgently. Another interpretation of this result could be that the belief of 29.2 per cent of the participants that there is no threat from HIV/AIDS to their businesses, might stem from the fact that some of them have strategies in place to minimise/ eliminate the risk factor. The latter interpretation is supported by the responses described in point 6 below.
5. 71 per cent (76) of the respondents indicated that HIV/AIDS has had no effect on their businesses, 26.2 per cent (28) said the epidemic had affected their sales negatively, while 2.8 per cent (3) said it has boosted sales. Unfortunately the scope of this research did not allow for following up on these responses, but it would be worthwhile to do so to determine the reasons for these opinions. This could be captured in follow-up interviews with the participants.

6. An alarming 78.5 per cent (84) of the participants recorded that they had no strategy in place to accommodate the threat of HIV/AIDS to their businesses. This means that although 97.2 per cent of them are aware of the epidemic (see point 1 above), most of them have no strategies in this regard. This matter needs serious attention. Comparing this result with that of point 4 above, the 21.5 per cent of the participants who do have strategies in place to accommodate the threat of HIV/AIDS, may form part of those (29.9 per cent) who believe that the pandemic holds no risk for their businesses and thus regard their existing strategies as highly effective. A follow-up investigation to clarify this would be useful.

7. 61.7 per cent (66) of the respondents indicated that they have made efforts to increase the awareness of their employees of HIV/AIDS, while the remainder have not. This could be interpreted as a lack of social responsibility towards employees on the part of this remaining 38.3 per cent. However, when considering this with the next set of responses, only a small percentage of respondents (possibly 7.5 per cent) could be suspected of this.

8. 54.2 per cent (58) of the respondents are aware of a HIV/AIDS awareness campaign in their community and the remainder is not. This could explain the responses reflected in point 7 above. This set of results could also point to a shortage of awareness campaigns in that specific area and this warrants further investigation. 
9. The vast majority of the participants believe that the government has an important role to play in combating HIV/AIDS.

- 96.3 per cent indicated that they believe the disease is of national concern and that it is the responsibility of the government to eradicate it. This displays a worrying attitude, as there is no indication of taking personal or corporate responsibility regarding either the prevention or the management of the epidemic.

- 72 per cent indicated that the government should increase the budget for research on HIV/AIDS. This could be a reflection of a less superficial concern about the epidemic than that indicated in the latter item. However, when comparing the two percentages involved ( 96.7 per cent and 72 per cent), this less superficial concern would be applicable to at most 3.3 per cent respondents (100 to 96.7 per cent).

- 49.5 per cent believed that the government should subsidise businesses whose employees have contracted HIV/ AIDS. This belief could be interpreted as another indication of the unwillingness to take responsibility for preventing, combating or managing the disease.

10. Most of the respondents (73.8 per cent (79)) believe that the survival of their businesses would be in jeopardy as soon as their percentage client loss exceeds 25 per cent. The mode ( 23 respondents) is on a low 10 per cent client loss and the median is at 20 per cent client loss. The perception that such low percentages of client loss would be fatal for the survival of the businesses could be attributed to the fact that all the businesses involved are small businesses and they operate on a low profit/ high turnover principle. A small drop in the number of clients would result in a decrease in the turnover and in turn this would affect profits negatively. The ripple effect of significant numbers of small businesses going under financially on the individual owner/manager, his/her family and the community would be devastating. This phenomenon is an example of one of the negative effects the HIV/AIDS pandemic would have on the non-infected population.

11. Finally, only 4 (3.7 per cent) of the respondents confirmed that they have an idea of what the impact of HIV/AIDS would be on their communities; a most alarming 96.3 per cent did not have any idea of the likely impact of the pandemic on their communities.

The above reporting and interpretation of the research results reflect a number of trends, perceptions and attitudes in the sample involved in this research. On the positive side is the very high awareness of the sample of the HIV/AIDS pandemic, the apparent confidential relationship some employees have with their employers regarding their HIV/AIDS status, the possibility that slightly more than one-fifth of the respondents might have an effective strategy in place that minimises/eliminates the risk factor that HIV/AIDS has for a business and the effort made by almost two-thirds of the sample to increase the awareness of their employees of the pandemic.

Some of the more worrying aspects are the lack of knowledge business managers and owners have of their employees' HIV/AIDS awareness, the apparent lack of detailed knowledge of the disease and its impact on the community, the negative effect the disease has on some of the businesses, the very high percentage of businesses that do not have a strategy in place to accommodate the threat of HIV/AIDS, the lack of effort to increase the awareness of employees of the pandemic in a third of the businesses, the absence of or lack of knowledge about the presence of HIV/AIDS awareness campaigns in the community, the abdicating of responsibility regarding the pandemic to the government, and the vulnerability of the survival of the businesses to the loss of clients. 


\section{6}

\section{Recommendations}

The following recommendations are made based on the research results:

- Information campaigns on HIV/AIDS, targeting small enterprises in the rural areas of the country, must be intensified. These campaigns must not only focus on increasing awareness of the pandemic, but must also provide specialised information on its impact on the macro, meso and micro levels of the economy as well as on the community.

- Owners/managers of small enterprises in the rural areas must be targeted for training in educating their employees on HIV/ AIDS. The apparent confidential relationship existing between the employers and employees as indicated by the research would be a very useful platform for this purpose.

- Specialised training must be provided to these owners/managers in creating and implementing strategies to cope with outside threats, such as HIV/AIDS, to their businesses.

- The responses to question 9 of the questionnaire indicate that most of the respondents believe that HIV/AIDS is a national concern and that government should take responsibility for creating and implementing a strategy against it; many also believe that an expanded government budget is needed for this and almost half of the respondents want government to subsidise businesses which have HIV positive employees. It is therefore recommended that government play a greater role in the combating of HIV/ AIDS.

The research results and above recommendations have implications regarding further actions to be taken. These include:

- The data analysis (point 5) indicated that further research needs to be carried out on respondents' perceptions of the nature of the effect of HIV/AIDS on their sales, viz.

no effect / negative effect / positive effect. Information gathered on this aspect could provide pointers for drafting their own business strategies.

- A detailed campaign needs to be created and implemented, targeting small enterprise owners and managers in the rural areas of the country. Such a campaign must address the issues that have been uncovered by this research. It must cover HIV/AIDS awareness, the impact the latter can be expected to have on the community and the economy in which these enterprises operate, and the training of owners/ managers in educating their employees on these issues.

- A model needs to be devised that could be used by owners and managers of these small enterprises to devise strategies for coping with the threat of HIV/AIDS to their businesses; assistance with its implementation also needs to be considered.

- The above recommendations need to be applied to similar populations worldwide.

7

\section{Conclusion}

The research reported on has uncovered some new nuances to the existing knowledge on HIV/ AIDS. These need to be accommodated in the HIV/AIDS landscape and included in planning for combating the pandemic. The latter three recommendations warrant special attention. In an attempt to address the latter at least partially, the authors have proceeded to develop a model to assist small enterprises in devising strategies to cope with HIV/AIDS.

\section{References}

1 BARNETT, T. \& WHITESIDE, A. (2002) AIDS in the Twenty-First Century ( $1^{\text {st }}$ ed.) Palgrave Macmillan: New York.

2 BENNETT, J. (2003) "Chemical sector takes up challenge" Sunday Times Business Times, 30 November: 11. 
3 BLESS, C. \& HIGSON-SMITH, C. (1995) Fundamentals of Social Research Methods: An African Perspective ( $2^{\text {nd }}$ ed.) Juta: Kenwyn.

4 EMDON, C. (2003) "Only mutual effort will stem the tide", Sunday Times Business Times, 17 August: 6.

5 KEETON, C. (2003a) "Aids: most companies are in the dark", Sunday Times Business Times, 10 August: 3 .

6 KEETON, C. (2003b) "Finally, business faces up to HIV/Aids reality", Sunday Times Business Times, 23 November: 6.

7 KEETON, C, (2004) "Statistics do bear grim testimony to Aids horror", Sunday Times, 18 January: 18 .

8 MBEKI, Z. (2001) "Impending catastrophe revisited", Sunday Times Lovelife: 13.
9 McMILLAN, J.H. \& SCHUMACHER, S. (1993) Research in Education: a Conceptual Introduction, HarperCollins: New York.

10 PROCTOR, T. (2000) Essentials of Marketing Research, Prentice Hall: London.

11 SEKARAN, U. (2000) Research Methods for Business, New York: Wiley.

12 STRUWIG, F.W. \& STEAD, G.B. (2001) Planning, Designing and Reporting Research, Maskew Miller Longman: Cape Town.

13 SUDMAN, S. \& BLAIR, E. (1998) Marketing Research, McGrawHill: Boston.

14 UNAIDS. Website: www.unaids.org.

15 VAN ROOYEN, K. \& THE TELEGRAPH (2004) "HIV/Aids figures overestimated" Sunday Times, 11 January: 1.

16 WHITESIDE, A. \& SUNTER, C. (2000) AIDS: The Challenge for South Africa ( $1^{\text {st }}$ ed.) Tafelberg: Cape Town. 